\title{
Hypothermia as a cause of death in British Columbia, 1998-2012: a descriptive assessment
}

\author{
Joanne Stares MHSc, Tom Kosatsky MD
}

Abstract

Background: Hypothermia can result from exposure to cold or as a consequence of underlying physiologic vulnerabilities. Who, where, when and how British Columbians (and Canadians) die of hypothermia have received little research attention. The objective of this study was to describe the epidemiology of mortality due to hypothermia among residents of British Columbia.

Methods: We examined all records in the death registry of the British Columbia Vital Statistics Agency between 1998 and 2012 that had an underlying or contributing cause of death coded for hypothermia or exposure to excessive natural cold.

Results: Hypothermia or exposure to excessive natural cold was found to be the underlying or contributing cause in 384 deaths between 1998 and 2012. Mean age of decedents was 52 (SD 20.78) years and 73.2\% were male. The annual death rate for hypothermia increased with age, ranging from 0.3 per 100000 population among people aged 1-34 years to 1.6 per 100000 population among those older than 75 years of age. The highest annual death rate occurred among older males (2.1 per 100000 population) followed by older females (1.3 per 100000 population). Although hypothermia-related deaths occurred year-round, $45.9 \%$ occurred during winter months (December, January and February) and, in particular, on days with lower temperatures (mean $0.56^{\circ} \mathrm{C}$ ). Use of alcohol (40.1\%) and other psychoactive substances (22.7\%) were the most common additional causes of death identified among deaths due to hypothermia. Areas of British Columbia with the lowest population density or lowest socioeconomic status were found to have the highest crude hypothermia-related mortality rates.

Interpretation: Our results showed that older people are at higher risk of hypothermia-related death. Among residents of British Columbia who died of hypothermia, the most frequent additional causes of death were alcohol and nonalcohol psychoactive substances. However, further assessment of both the occurrence and determinants of mortality due to hypothermia are needed to inform measures to reduce its impact.

$\mathrm{H}$ ypothermia is a condition where core body temperature falls below that required for the sustained functioning of vital organs (typically described as $\leq 35^{\circ} \mathrm{C}$ ). Many cases of hypothermia are unintentional, such as immersion in cold water, injury or unprotected exposure. ${ }^{1}$ Several physiologic and behavioural vulnerabilities increase risk for hypothermia, including the extremes of age, alcohol consumption, drug ingestion and chronic disease. ${ }^{1}$

Little is known about mortality caused by hypothermia in Canada. Between April 1994 and March 1997 most admissions to hospital and deaths in Montréal directly related to environmental temperature injury were found to be due to cold. ${ }^{2}$ Gaps in our understanding of the extent of hypothermia mortality and its climatic and behavioural causes in a Canadian context limit our capacity to prevent it. The objective of this study was to describe the epidemiology of mortality due to hypothermia among residents of British Columbia.

\section{Methods}

\section{Setting}

We abstracted electronic records, which had identifying information removed, for hypothermia-related deaths that occurred among residents of BC between 1998 and 2012 during March 2013.

\section{Study design}

We conducted a descriptive study of entries abstracted from medical certificates of death. Data were analyzed in

Competing interests: None declared.

This article has been peer reviewed.

Correspondence to: Tom Kosatsky, tom.kosatsky@bccdc.ca

CMAJ Open 2015. DOI:10.9778/cmajo.20150013 
the context of ecologic factors related to the physical and social environments in which the deaths occurred.

\section{Sources of data}

Mortality records were extracted from the British Columbia Vital Statistics Agency. This file contains information recorded on medical certificates of death for all deaths that occur in the province. Date of death, age and sex of the deceased, local health area and postal code of residence, location of death (categorized as home, hospital, residential institution or other specified locality), and causes of death were accessed. Location of death was available in this data set only after 2008. Only one underlying cause of death and up to 9 contributing causes of death are recorded. We defined a death to be related to hypothermia if the International Statistical Classification of Diseases and Related Health Problems, 10th revision codes (ICD-10) T68 (hypothermia) or $\mathrm{X} 31$ (exposure to excessive natural cold) were present on the death certificate as the underlying cause or as a contributing cause of death. We considered deaths where hypothermiarelated diagnoses were certified as the underlying cause of death as primary hypothermia mortalities. Deaths where hypothermia-related diagnoses were present on the certification of death as a contributing cause were considered secondary hypothermia mortalities.

Complete daytime mean apparent temperature measurements $\left({ }^{\circ} \mathrm{C}\right)$ were obtained from data collected at 29 weather stations across the province, 1 weather station in Alberta near the BC border and 1 in Yukon near the BC border.

We obtained areas $\left(\mathrm{km}^{2}\right)$ for each local health area from the shape files of BC Stats. ${ }^{3}$ We obtained the population sizes for the province and local health areas from BC Stats' SubProvincial Population Projections data set. ${ }^{4} \mathrm{We}$ calculated population density by dividing the mean population for each local health area during 1998-2012 by its area.

We obtained data for 78 of 89 local health areas from the 2011 Regional Socioeconomic Index (BC Stats). ${ }^{5}$ Data were not available for the remaining 11 local health areas.

Temperature measurements on the day of death were linked to decedents by postal code of residence. Each of 89 local health areas in $\mathrm{BC}$ were linked to temperature measurements collected from 1 of 31 weather stations or were deterministically imputed from temperatures. ${ }^{6}$ An average of the hourly temperatures from the 2 nearest weather stations was used in situations where $50 \%$ or less of the hourly records was available for imputation. Local health areas were matched to weather stations by choosing the station nearest the population-weighted centre of the health area or by geographic similarity; where the population centre was distant from a weather station, the nearest weather station that best represented the geographic location of the population centre was selected. ${ }^{6}$

We excluded deaths involving nonresidents of BC from these analyses. Residents of BC with unknown areas of residence were excluded only from ecological analyses. Deaths with hypothermia codes specific to newborns or "hypothermia of man-made origin" were excluded.

\section{Statistical analysis}

Analyses were descriptive in nature, relating to counts, proportions, averages and crude annual mortality rates. Maps, data linkages and calculations were performed using $\mathrm{R}$ Studio. Rates were calculated for age groups 1-34, 35-64, 65-74, and 75 years and older, by sex, for both primary and secondary hypothermia deaths. Rates were also calculated for younger residents $(<75 \mathrm{yr}$ of age) and older residents $(\geq 75 \mathrm{yr}$ of age) at time of death. Additional nonhypothermia causes of death also present on the death certificate were selected based on the frequency of their occurrence in our data set. We also determined the number and proportion of hypothermia deaths that occurred on days where the mean apparent temperature $\left({ }^{\circ} \mathrm{C}\right)$ was $-20^{\circ} \mathrm{C}$ or lower, -20 to $-10^{\circ} \mathrm{C},-10$ to $-5^{\circ} \mathrm{C},-5$ to $0^{\circ} \mathrm{C}, 0-5^{\circ} \mathrm{C}, 5-10^{\circ} \mathrm{C}, 10-20^{\circ} \mathrm{C}$, and greater than $20^{\circ} \mathrm{C}$.

Spearman rank correlations and $95 \%$ confidence intervals (CIs) were calculated to assess the relationship between annual mortality rates and population density, and the Regional Socioeconomic Index. A nonparametric estimate was required because the relationships between the variables were not linear. Confidence intervals were calculated using the Fisher $z$ transformation.

\section{Results}

There were 384 hypothermia-related deaths among residents of BC between January 1998 and December 2012. Nineteen deaths occurred among nonresidents of BC and were excluded from subsequent analyses. The local health area of residence was not recorded for $4 \mathrm{BC}$ residents.

We determined that 157 deaths $(40.9 \%)$ were primary hypothermia deaths and 227 deaths (59.1\%) were secondary. Mean age was 52 (standard deviation [SD] 20.78) years with $70.0 \%$ of mortalities occurring among those residents 64 years of age or less (Table 1). Overall, the annual mortality rate was 0.6 per 100000 population. The annual mortality rate increased with age, ranging from 0.3 per 100000 population among residents aged $1-34$ years to 1.6 per 100000 population among those over 75 years of age. Most of the decedents $(n=281,73.2 \%)$ were male. On average, females were almost 8 years older at time of death relative to males. However, the highest annual mortality rate occurred among older males (2.1 per 100000 population) followed by older females (1.3 per 100000 population).

Most deaths ( $n=176,45.9 \%)$ occurred during winter months, followed by spring, fall and summer, respectively (Table 2). There were relatively more hypothermia-related deaths during winter and spring among older people. The proportion of deaths among older people that occurred during summer $(5.9 \%)$ was one-half that observed for decedents less than 75 years of age. The mean apparent temperature on the day of death was $0.498^{\circ} \mathrm{C}$ (SD 10.583), with $43 \%$ of deaths occurring at ambient temperatures between -5 and $5^{\circ} \mathrm{C}$ (Figure 1).

The most frequent additional causes of death were alcohol $(n=154,40.1 \%)$ and nonalcohol psychoactive substances $(n=$ 


\section{OPEN}

$87,22.7 \%)$, followed by heart disease $(n=75,19.5 \%)$, immersion $(n=60,15.6 \%)$ and injury $(n=54,14.1 \%)$ (Table 3$)$. Among decedents less than 75 years of age $(n=316)$, the most frequent additional causes of death were alcohol $(n=148$, $46.8 \%)$ and nonalcohol psychoactive substances $(n=87$, $25.6 \%)$, followed by immersion $(n=57,18.0 \%)$, heart disease $(n=49,15.5 \%)$ and injury $(n=41,13.0 \%)$. Among older decedents $(n=68)$, the most frequent additional causes of death were heart disease $(n=26,38.2 \%)$, falls $(n=17,25.0 \%)$, injury $(n=13,19.1 \%)$, mental and behavioural disorders not related to substance use $(n=12,17.6 \%)$, and diseases of the respiratory system $(n=12,17.6 \%)$.

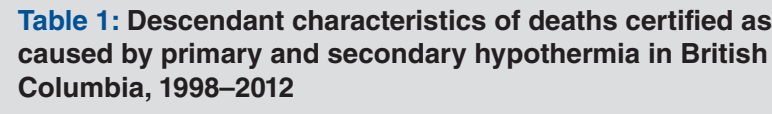

\begin{tabular}{|c|c|c|c|}
\hline Characteristics & $\begin{array}{c}\text { No. }(\%) \text { of } \\
\text { deaths } \\
n=384\end{array}$ & $\begin{array}{l}\text { No. of deaths } \\
\text { per year, } \\
\text { mean } \pm \text { SD }\end{array}$ & $\begin{array}{c}\text { Crude annual } \\
\text { mortality rate } \\
\text { (per } 100000 \\
\text { population) }\end{array}$ \\
\hline \multicolumn{4}{|l|}{ Cause } \\
\hline $\begin{array}{l}\text { Primary } \\
\text { hypothermia }\end{array}$ & $157(40.9)$ & $10.467 \pm 3.815$ & 0.2 \\
\hline $\begin{array}{l}\text { Secondary } \\
\text { hypothermia }\end{array}$ & $227(59.1)$ & $15.133 \pm 3.777$ & 0.3 \\
\hline \multicolumn{4}{|l|}{ Age, yr } \\
\hline $1-34$ & $85(22.1)$ & $5.667 \pm 2.582$ & 0.3 \\
\hline $35-64$ & $184(47.9)$ & $12.267 \pm 3.262$ & 0.7 \\
\hline $65-74$ & 47 (12.2) & $3.133 \pm 1.727$ & 1.0 \\
\hline$\geq 75$ & 68 (17.7) & $4.533 \pm 1.552$ & 1.6 \\
\hline \multicolumn{4}{|l|}{ Sex } \\
\hline Male & $281(73.2)$ & $18.733 \pm 4.621$ & 0.9 \\
\hline$<75 \mathrm{yr}$ & $245(63.8)$ & $16.333 \pm 4.065$ & 0.8 \\
\hline$\geq 75 \mathrm{yr}$ & $36(9.4)$ & $2.4 \pm 1.594$ & 2.1 \\
\hline Female & $103(26.8)$ & $6.867 \pm 2.799$ & 0.3 \\
\hline$<75 \mathrm{yr}$ & $71(18.5)$ & $4.733 \pm 2.251$ & 0.2 \\
\hline$\geq 75 \mathrm{yr}$ & $32(8.3)$ & $2.133 \pm 1.302$ & 1.3 \\
\hline $\begin{array}{l}\text { All deaths } \\
\text { caused by } \\
\text { hypothermia }\end{array}$ & & $25.6 \pm 4.437$ & 0.6 \\
\hline
\end{tabular}

Most hypothermia-related deaths occurred at locations other than the home, hospital or residential institution $(n=$ $86,64.2 \%)$ (Table 4). Among older people, most deaths $(n=$ $10,38.5 \%$ ) occurred in hospital. Among primary hypothermia mortalities, most deaths occurred at locations other than the home, hospital or residential institution $(n=49,72.1 \%)$, followed by death was at home $(n=12,17.6 \%)$. Most secondary hypothermia deaths occurred at locations other than the home, hospital or residential institution $(n=37,56.1 \%)$, followed by hospital ( $n=21,31.8 \%)$.

Crude mortality rates ranged from 0 to 19.1 per 100000 population per year in local health areas across the province (Figure 2). The highest crude mortality rates occurred in relatively more rural and remote local health areas. Among the 79 local health areas where there were hypothermia-related mortalities, the lowest crude mortality rates occurred in the Greater Vancouver Area.

Figure 3 shows that population density was inversely correlated (nonlinearly) to the annual mortality rate. The correlation coefficient for this relationship is -0.33 (95\% CI -0.50 to 0.12 ).

Figure 4 shows Regional Socio-economic Index scores plotted against the annual mortality rate. The correlation

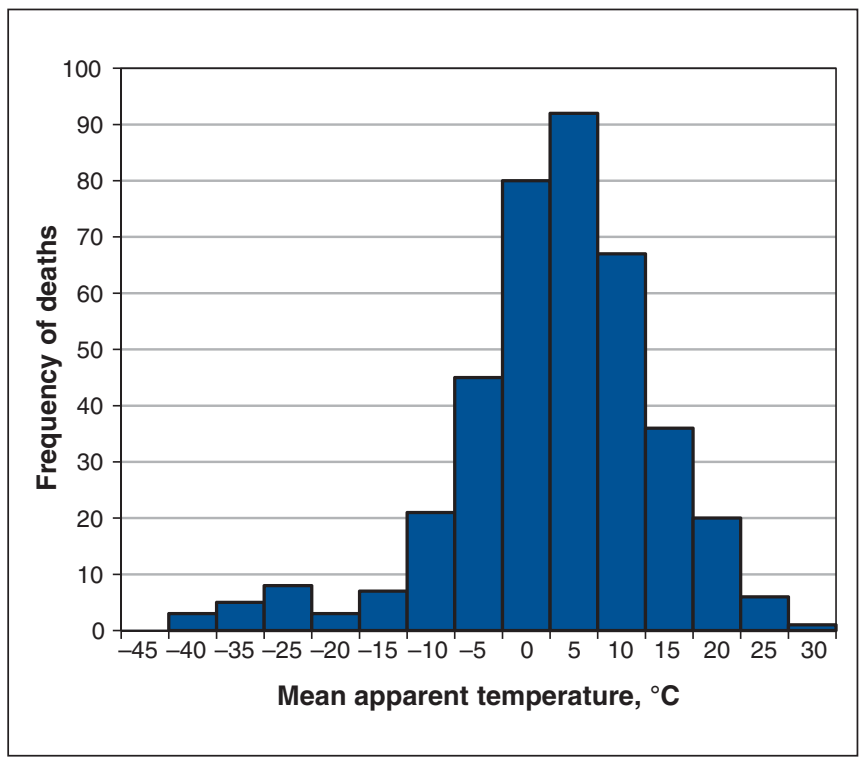

Figure 1: Frequency of hypothermia mortality in British Columbia (1998-2012), by mean apparent temperature on day of death.

Table 2: Deaths due to hypothermia in British Columbia (1998-2012), by season

\begin{tabular}{|lccccc|}
\hline & \multicolumn{3}{c|}{ No. (\%) of patients } \\
\cline { 2 - 6 } Months & $\begin{array}{c}\text { Male } \\
n=281\end{array}$ & $\begin{array}{c}\text { Female } \\
n=103\end{array}$ & $\begin{array}{c}\text { Age }<75 \text { yr } \\
n=316\end{array}$ & $\begin{array}{c}\text { Age } \geq 75 \text { yr } \\
n=68\end{array}$ & $\begin{array}{c}\text { Total no. of deaths } \\
n=384\end{array}$ \\
\hline Winter (December-February) & $129(45.9)$ & $47(45.6)$ & $144(45.6)$ & $32(47.1)$ & $176(45.8)$ \\
\hline Spring (March-May) & $67(23.8)$ & $25(24.3)$ & $73(23.1)$ & $19(27.9)$ & $4(5.9)$ \\
\hline Summer (June-August) & $29(10.3)$ & $13(12.6)$ & $38(12.0)$ & $13(19.1)$ & $42(10.9)$ \\
\hline Fall (September-November) & $56(19.9)$ & $18(17.5)$ & $61(19.3)$ & & $74(19.3)$ \\
\hline
\end{tabular}


Table 3: Additional causes of death in British Columbia, 1998-2012

\begin{tabular}{|c|c|c|c|}
\hline Group & Most frequent additional causes of death & $n(\%)$ & $\begin{array}{l}\text { No. of deaths per year, } \\
\text { mean } \pm \text { SD }\end{array}$ \\
\hline \multirow[t]{5}{*}{ Primary, $n=157$} & Alcohol & $83(52.9)$ & $5.533 \pm 2.722$ \\
\hline & Heart disease & $34(21.7)$ & $2.266 \pm 1.944$ \\
\hline & Nonalcohol psychoactive substances & $31(19.7)$ & $2.067 \pm 1.502$ \\
\hline & $\begin{array}{l}\text { Mental and behavioural disorders not related to substance } \\
\text { use }\end{array}$ & $20(12.7)$ & $1.333 \pm 0.899$ \\
\hline & Syncope and collapse & $10(6.4)$ & $0.667 \pm 0.724$ \\
\hline \multirow[t]{6}{*}{ Secondary, $n=227$} & Alcohol & $71(31.3)$ & $4.733 \pm 2.219$ \\
\hline & Immersion & $60(26.4)$ & $4.0 \pm 2.171$ \\
\hline & Nonalcohol psychoactive substances & $56(24.7)$ & $3.733 \pm 2.52$ \\
\hline & Injury & $50(22.0)$ & $3.333 \pm 1.759$ \\
\hline & Heart disease & $41(18.1)$ & $2.733 \pm 1.751$ \\
\hline & Water transportation accidents & $41(18.1)$ & $2.733 \pm 2.219$ \\
\hline \multirow[t]{5}{*}{ Age $<75$ yr $; n=316$} & Alcohol & $148(46.8)$ & $9.987 \pm 2.503$ \\
\hline & Nonalcohol psychoactive substances & $81(25.6)$ & $5.4 \pm 2.667$ \\
\hline & Immersion & $57(18.0)$ & $3.8 \pm 1.859$ \\
\hline & Heart disease & $49(15.5)$ & $3.267 \pm 2.433$ \\
\hline & Injury & $41(13.0)$ & $2.733 \pm 1.486$ \\
\hline \multirow[t]{5}{*}{ Age $\geq 75 \mathrm{yr} ; n=68$} & Heart disease & $26(38.2)$ & $1.733 \pm 1.534$ \\
\hline & Falls & $17(25.0)$ & $1.133 \pm 1.06$ \\
\hline & Injury & $13(19.1)$ & $0.867 \pm 0.834$ \\
\hline & $\begin{array}{l}\text { Mental and behavioural disorders not related to substance } \\
\text { use }\end{array}$ & $12(17.6)$ & $0.8 \pm 0.676$ \\
\hline & Diseases of the respiratory system & $12(17.6)$ & $0.8 \pm 0.862$ \\
\hline \multirow{5}{*}{$\begin{array}{l}\text { All deaths due to } \\
\text { hypothermia, } n=384\end{array}$} & Alcohol & $154(40.1)$ & $10.267 \pm 2.656$ \\
\hline & Nonalcohol psychoactive substances & $87(22.7)$ & $5.8 \pm 2.859$ \\
\hline & Heart disease & 75 (19.5) & $5.0 \pm 2.752$ \\
\hline & Immersion & $60(15.6)$ & $4.0 \pm 2.171$ \\
\hline & Injury & $54(14.1)$ & $3.6 \pm 1.639$ \\
\hline
\end{tabular}

Table 4: Primary and secondary hypothermia-related deaths in British Columbia (2008-2012), by age and location of death

No. $(\%)$ of deaths

\begin{tabular}{|c|c|c|c|c|c|c|}
\hline \multirow[b]{2}{*}{$\begin{array}{l}\text { Hypothermia } \\
\text { mortality type }\end{array}$} & \multirow[b]{2}{*}{ Age category } & & & & & \multirow[b]{2}{*}{$\begin{array}{c}\text { Total no. of } \\
\text { deaths }\end{array}$} \\
\hline & & Home & Hospital & $\begin{array}{l}\text { Other specified } \\
\text { locality }\end{array}$ & $\begin{array}{l}\text { Residential } \\
\text { institution }\end{array}$ & \\
\hline \multirow[t]{3}{*}{ Primary } & $<75 \mathrm{yr}$ & $9(15.5)$ & $5(8.6)$ & $44(75.6)$ & $0(0)$ & 58 \\
\hline & $\geq 75 \mathrm{yr}$ & $3(30.0)$ & $1(10.0)$ & $5(50.0)$ & $1(10.0)$ & 10 \\
\hline & All ages & $12(17.6)$ & $6(8.8)$ & $49(72.1)$ & $1(1.5)$ & 68 \\
\hline \multirow[t]{3}{*}{ Secondary } & $<75 \mathrm{yr}$ & $4(8.0)$ & $12(24.0)$ & $33(66.0)$ & $1(2.0)$ & 50 \\
\hline & $\geq 75 \mathrm{yr}$ & $2(12.5)$ & $9(56.2)$ & $4(25.0)$ & $1(6.2)$ & 16 \\
\hline & All ages & $6(9.1)$ & $21(31.8)$ & $37(56.1)$ & $2(3.0)$ & 66 \\
\hline \multirow[t]{3}{*}{ All } & $<75 \mathrm{yr}$ & $13(12.0)$ & 17 (15.7) & 77 (71.3) & $1(0.9)$ & 108 \\
\hline & $\geq 75 \mathrm{yr}$ & $5(19.2)$ & $10(38.5)$ & $9(34.6)$ & $2(7.7)$ & 26 \\
\hline & All ages & $18(13.4)$ & $27(20.1)$ & $86(64.2)$ & $3(2.2)$ & 134 \\
\hline
\end{tabular}


coefficient for this relationship is 0.46 (95\% CI 0.26 to 0.62 ). Because a lower score indicates higher regional socioeconomic status, this illustrates that local health areas characterized by higher socioeconomic status have the lowest annual mortality rates. No index value was available in 2011 for some of local health areas with the highest mortality rates.

\section{Interpretation}

Based on death certificates, the annual mortality rate for hypothermia among residents of $\mathrm{BC}$ was 0.6 per 100000 population, which equates to about 25.6 deaths per year. Risk of hypothermia-related mortality was found to be associated with male gender, advanced age, winter months and cool temperatures, and alcohol or drug use. Rurality and regional socioeconomic status were also found to be associated with hypothermia-related mortality; however, this relationship is not strong and is based on small numbers of deaths. Although alcohol and nonalcohol substance use was associated with $40.1 \%$ and $22.7 \%$, respectively, of all hypothermia deaths for
$\mathrm{BC}$ residents, heart disease, falls and injury were most commonly associated with hypothermia-related deaths among decedents aged 75 years and older. In addition, we identified that most hypothermia-related mortalities in decedents less than 75 years of age occurred in locations other than the home, hospital or residential institution, whereas a hospital was the most common location of death among older people.

Trends in hypothermia-related mortality in BC do not deviate from what has been reported elsewhere. The crude annual hypothermia mortality rate for BC is higher than recent estimates from the United States $(0.20$ per 100000 population $)^{7}$ and similar to what was reported for New Zealand (0.54 per 100000 population), ${ }^{8}$ but lower than what was reported for the Republic of Ireland (1.81 per 100000 population). ${ }^{9}$ Studies have also indicated that the incidence of injury caused by hypothermia is much higher than that of hypothermia-related mortality. ${ }^{8,9}$ This suggests that beyond our review of hypothermia-related deaths, it is likely that there are more $\mathrm{BC}$ residents who have suffered important hypothermia-associated morbidity.

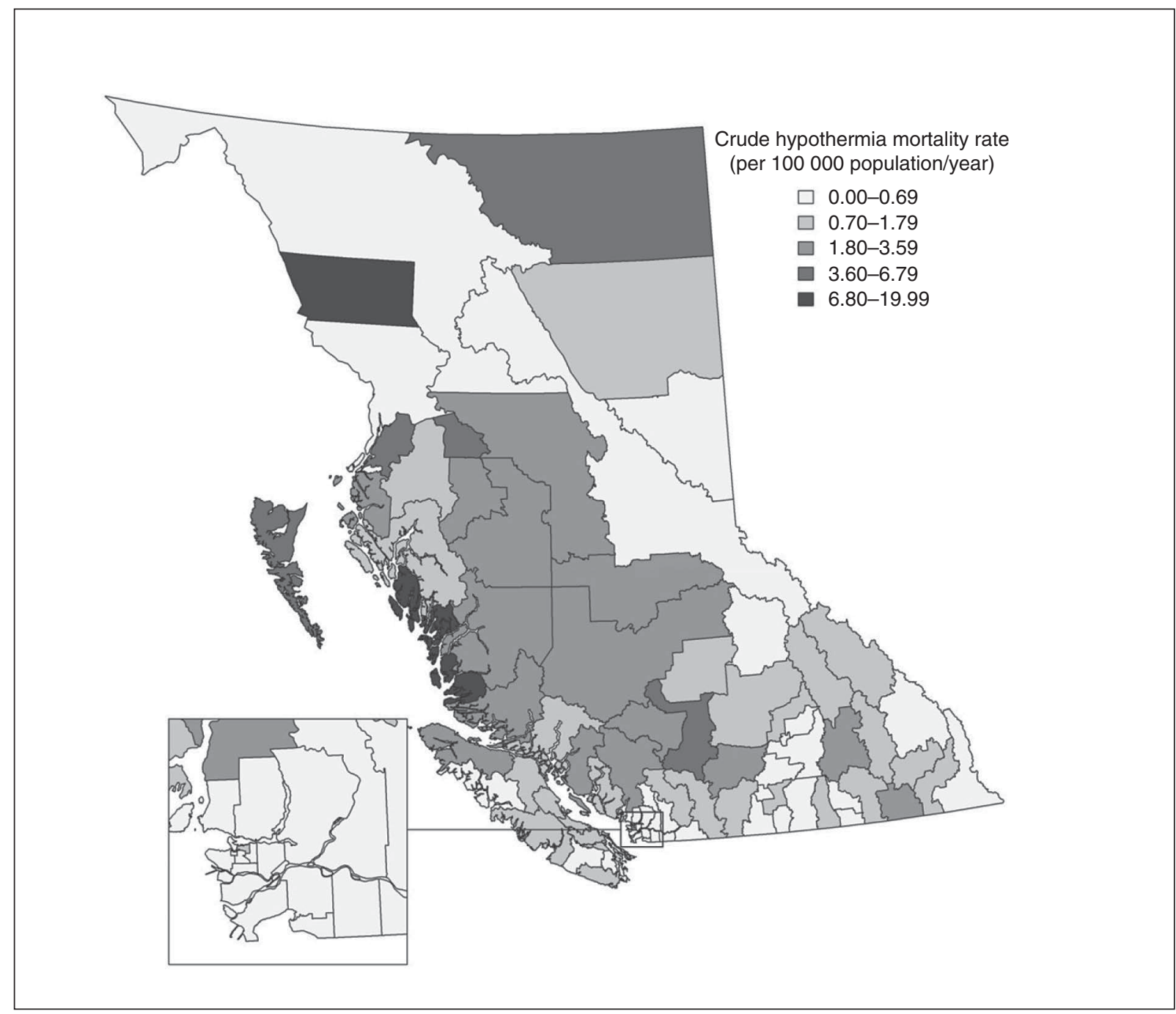

Figure 2: Crude hypothermia mortality rate per 100000 population per year in British Columbia (1998-2012), by local health area. 
Factors identified as being associated with mortality resulting from hypothermia in BC also have been associated with hypothermia mortality elsewhere in the world. ${ }^{7-11}$ Although deaths caused by hypothermia are not unique to areas characterized by cold climate, ${ }^{10,12}$ it has been shown to be most frequent during the winter months and at cooler temperatures. ${ }^{9}$ The case fatality proportion for hypothermia also has been shown as negatively associated with temperature, ranging from $13 \%$ at temperatures $\geq 15^{\circ} \mathrm{C}$ to $44 \%$ at temperatures of $-1^{\circ} \mathrm{C}$ or lower. ${ }^{9}$ Other studies have indicated that the burden

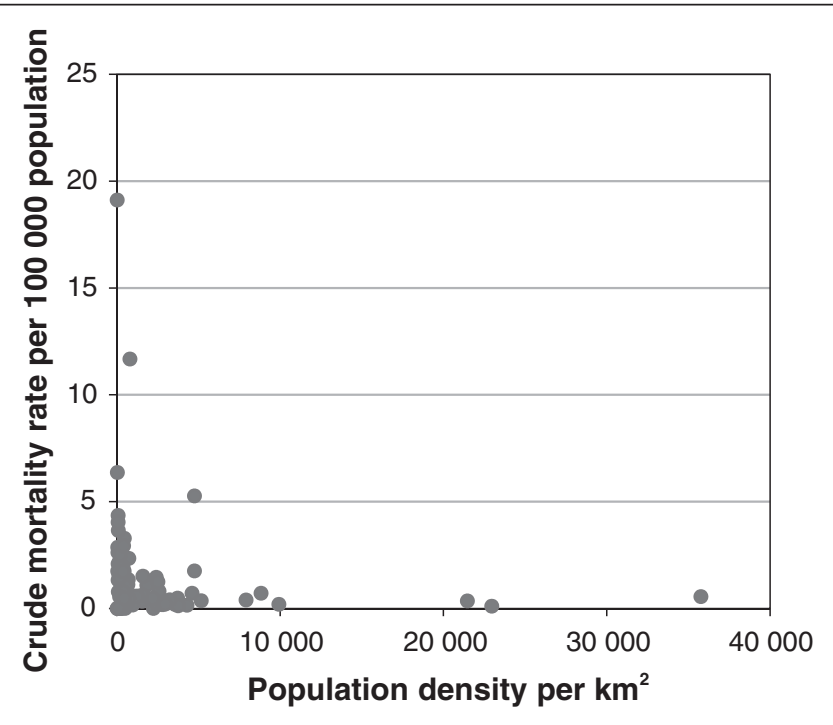

Figure 3: Population density of local health area versus crude mortality rate in British Columbia (1998-2012) $(n=89$, Spearman rank correlation coefficient $\left(r_{\mathrm{s}}\right)=-0.33,95 \%$ confidence interval -0.50 to -0.12$)$.

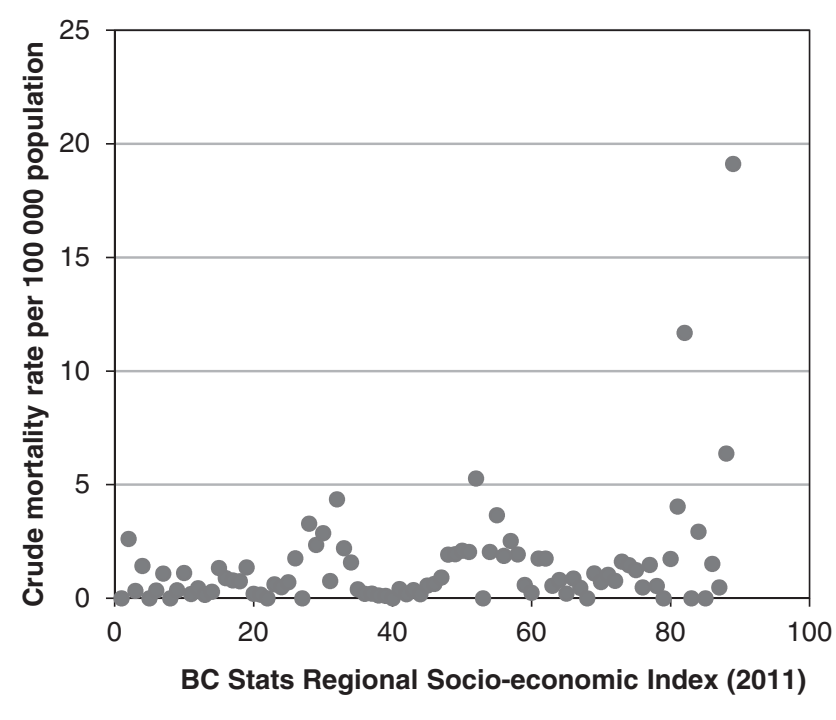

Figure 4: BC Stats Regional Socio-economic Index (2011) values for local health area versus crude mortality rate in British Columbia (1998-2012). A higher index value indicates lower regional socioeconomic status ( $n=77$, Spearman rank correlation coefficient $\left(r_{s}\right)=0.46,95 \%$ confidence interval $=0.26$ to 0.62$)$. of hypothermia-related mortality is greatest for older people, particularly older men. ${ }^{7,-13}$ Ethnicity has been identified as an effect modifier: in North America, age-specific mortality rates are higher for nonwhite populations, with the highest rates occurring among older nonwhite men, followed by older nonwhite women. ${ }^{10,11}$ For location of death, it has been shown that most hypothermia deaths among persons less than 64 years of age occur outside the home (76\%), whereas the most hypothermia deaths among persons 65 years of age or older occur in a domestic setting (87\%). ${ }^{8}$ Taken together, these studies suggest that the occurrence of hypothermia may be as reflective of social factors as of factors related to climate.

There are several important limitations to the information presented here. First, our data set may not contain all hypothermia mortalities in BC. Only hypothermia mortalities with ICD-10 codes T68 (hypothermia) or X31 (exposure to excessive natural cold) recorded on the death certificate would have been captured. It is unknown how consistently the data for deaths caused by hypothermia or exposure to cold are captured, or how different practitioner practices for completing death certificates may impact our findings. In addition, given the association between hypothermia mortality and drug and alcohol use, inconsistent attribution of hypothermia may be particularly relevant in situations where overdose was identified as the underlying cause of death. Second, data on the decedent's place of residence (and location of exposure) at the time of death may not be accurately captured by the place of residence coded on the death certificate, particularly for members of the most vulnerable populations (homeless, transient or housing insecure). In addition, location of death was described crudely by the data we had available and was only recorded on the death certificate after 2008. Third, the populations in local health areas with the highest crude mortality rates were relatively small, and counts of hypothermia-related deaths in these areas were 5 or less. Although crude mortality rates in these local health areas are substantially higher if taken together, they are likely to be less stable than in other larger local health areas. Fourth, multiple diagnostic codes per category could be present on a death certificate. It is unknown how this might affect the trends identified in additional causes of death presented in this report.

\section{Conclusion}

Our results showed that older people are at higher risk of hypothermia-related death. Among residents of British Columbia who died of hypothermia, the most frequent additional causes of death were alcohol and nonalcohol psychoactive substances. Our results also illustrate a need to develop a better understanding of the occurrence of hypothermia in BC and in Canada. Future work should allow public health agencies to better estimate the burden of mortality and injury due to hypothermia, promote better understanding of vulnerabilities and at-risk populations and facilitate a better understanding of why people die from hypothermia in Canada. These objectives could be achieved by examining admissions to hospital, emergency department visits and ambulance calls to describe hypothermia-related injury; comparing the data of 
people who died of hypothermia with those who were admitted to hospital but did not die, to better identify risks for death; describing the occurrence of hypothermia in rural and urban settings separately; undertaking directed subgroup analyses, specifically for those living in poverty and marginalized populations; and studying the interplay between temperature and the social determinants of health as they relate to hypothermia mortality.

\section{References}

1. Weinberg AD. Hypothermia. Ann Emerg Med 1993;22:370-7.

2. Koutsavlis AT, Kosatsky T. Environmental-temperature injury in a Canadian metropolis. 7 Environ Health 2003;66:40-5.

3. Translations and data sets. Vancouver: Stats BC. 2015. Available: www.bcstats. gov.bc.ca /StatisticsBySubject/Geography/TranslationsDataSets.aspx (accessed 2015 Aug. 26).

4. Population projections, British Columbia-level and sub-provincial. Vancouver: Stats BC. 2015. Available: www.bcstats.gov.bc.ca/StatisticsBySubject/Demography/ PopulationProjections.aspx (accessed 2015 Aug. 26).

5. Socio-economic indices: local health area. Vancouver: Stats BC. 2015 (accessed 2015 Aug. 26). Available: www.bcstats.gov.bc.ca/StatisticsBySubject/SocialStatistics/ SocioEconomicProfilesIndices/SocioEconomicIndices/LHAReports.aspx.

6. Henderson S, Wan V, Kosatsky T. A preliminary examination of the association between cold weather mortality in British Columbia between 1986 and 2010: final report. Vancouver: BC Centre for Disease Control; 2012.

7. Centers for Disease Control and Prevention (CDC). Hypothermia-related deaths - United States, 2003-2004. MMWR Morb Mortal Wkly Rep 2005; $54: 173-5$.
8. Taylor NA, Griffiths R, Cotter J. Epidemiology of hypothermia: fatalities and hospitalisations in New Zealand. Aust N Z 7 Med 1994;24:705-10.

9. Herity B, Daly L, Bourke G, et al. Hypothermia and mortality and morbidity. An epidemiological analysis. F Epidemiol Community Health 1991;45:19-23.

10. Taylor AJ, McGwin G, Davis G, et al. Hypothermia deaths in Jefferson County, Alabama. Inj Prev 2001;7:141-5.

11. Rango N. Exposure-related hypothermia mortality in the United States, 197079. Am 7 Public Health 1984;74:1159-60.

12. Centers for Disease Control and Prevention (CDC). Hypothermia-related deaths: Georgia, January 1996-December 1997, and United States, 1979 1995. MMWR Morb Mortal Wkly Rep 1998;47:1037-40.

13. Taylor AJ, McGwin G. Temperature-related deaths in Alabama. South Med 7 2000;93:787-92.

Affiliations: Canadian Public Health Service (Stares), Public Health Agency of Canada, Ottawa, Ont.; Environmental Health Services, and National Collaborating Centre for Environmental Health (Kosatsky), BC Centre for Disease Control, Vancouver, BC

Contributors: Joanne Stares analyzed the data and drafted the article. Both of the authors contributed substantially to conception and design, interpreted the data, revised it critically for intellectual content, approved the final version to be published and agreed to act as guarantors of the work.

Acknowledgements: The authors thank Sarah Henderson (BC Centre for Disease Control) for her contributions to this study, which included data extraction, and for advising the authors during analysis and interpretation.

Supplemental information: For reviewer comments and the original submission of this manuscript, please see www.cmajopen.ca/content/3/4/ E352/suppl/DC1 